\title{
Use of the six-minute walk test in exercise prescription in male patients after coronary artery bypass surgery
}

\author{
Dorota Dolecińska ${ }^{1}$, Izabela Przywarska², Tomasz Podgórski ${ }^{3}$, Piotr Dylewicz ${ }^{4}$, Jacek Lewandowski ${ }^{1}$ \\ ${ }^{1}$ Department of Motor Organ Rehabilitation, Poznan University of Physical Education, Poznan, Poland \\ ${ }^{2}$ Department of Cardiological and Rheumatological Rehabilitation, Poznan University of Physical Education, Poznan, Poland \\ ${ }^{3}$ Department of Physiology and Biochemistry, Poznan University of Physical Education, Poznan, Poland \\ ${ }^{4}$ Institute of Health and Physical Education, Jan Amos Komenski State School of Higher Vocational Education, Leszno, Poland
}

Kardiochir Torakochir Pol 2020; 17 (4): 183-188

\begin{abstract}
Introduction: It is unclear whether it is possible to determine the training load on the basis of the 6-minute walk test (6-MWT) in patients after cardiac surgery with low tolerance of physical exercise.

Aim: Use of the 6-MWT to determine an individual initial training load in walking training on a treadmill in the early phase of cardiac rehabilitation in men after coronary artery bypass graft (CABG) surgery.

Material and methods: Twenty-two men aged 54 to 74 years, up to 3 months after CABG surgery participated in walking training on a treadmill (12-15 sessions). Patients underwent the initial and final treadmill exercise stress test (TEST) and the 6-MWT. Based on 6-MWT results, the initial training load was prescribed. Before the 6-MWT and 3 minutes after its completion, lactate concentration was determined.

Results: The 6-MWT distance increased from $420 \pm 80 \mathrm{~m}$ to $519 \pm 61 \mathrm{~m}(p<0.001)$, and the energy expenditure from $4.4 \pm 1.4 \mathrm{MET}$ to $6.3 \pm 1.3 \mathrm{MET}(p<0.001)$. There was a positive correlation between 6 -MWT distance and energy expenditure in the TEST before rehabilitation $(r=0.60, p=0.005)$, and after rehabilitation $(r=0.75, p<0.001)$. A negative correlation was found between the baseline 6-MWT distance and distance increment in the final 6-MWT $(r=-0.66, p=0.002)$. The 6-MWT did not induce hyperlactatemia.

Conclusions: The 6-MWT can be used in exercise intensity prescription, especially for determining the individual initial training load, load progression, as well as its correction during follow-up tests.
\end{abstract}

Key words: 6-minute walk test, cardiac rehabilitation, coronary artery bypass, lactate, walking training.

\section{Introduction}

The 6-minute walk test (6-MWT) is a simple tool for assessing exercise tolerance and adaptation to everyday activities. The test is safe for patients, easy to perform and to interpret, does not require specialized equipment or special training of personnel and the risk of complications is low. 6-MWT results enable the classification of patients for physical training of appropriate intensity; moreover, the test can also be used to assess the effectiveness of cardiac rehabilitation [1, 2]. However, it is still not clear whether it is possible to safely and effectively determine the training load on the basis of the 6-MWT in patients after cardiac surgery with low tolerance of physical exercise [2, 3].

According to current recommendations of the European Society of Cardiology, there is an urgent need for more accurate exercise prescription in different patient categories [4], particularly appropriate dose and type of physical activ- ity [5]. Likewise, the American College of Cardiology/American Heart Association strongly emphasizes the necessity of exercise individualization [6]. Many authors highlight in particular the need for more accurate tailoring of training intensity [1, 7-9].

The evidence points to the urgent requirement for developing new, individually tailored training programs characterized by maximum effectiveness with minimum risk of adverse events. For this reason, we developed a model of low intensity walking training in men in the early phase of cardiac rehabilitation after coronary artery bypass graft (CABG) surgery, in which the initial training load was determined on the basis of 6-MWT results. We focused on walking since it is one of the most common, utilitarian and natural activities of everyday life; moreover, it is very well tolerated by most patients [10]. The research was conducted with the participation of men after CABG surgery as it

Address for correspondence: Dorota Dolecińska PhD, Department of Motor Organ Rehabilitation, Poznan University of Physical Education, Poznan, Poland, phone: +48 6183551 40, e-mail: dorota_sobczak@op.pl Received: 4.08.2020, accepted: 24.10.2020. 
is the main cardiac surgery procedure performed in Poland [11]. Some of the results of our study were published in the previous paper [12].

\section{Aim}

The purpose of our study was to use the 6-MWT to determine an individual initial training load in walking training on a treadmill in the early phase of cardiac rehabilitation in male patients after CABG surgery.

\section{Material and methods \\ Study participants}

We recruited 22 consecutive patients aged 54 to 74 years after CABG surgery, who were admitted to the Cardiac Rehabilitation Ward of the Provincial Hospital in Poznan, Poland. This study was conducted in accordance with the amended Declaration of Helsinki. Poznan University of Medical Sciences Bioethics Committee approved the protocol (841/13) and written informed consent was obtained from all patients.

Inclusion criteria were male gender, CABG surgery performed in the last 3 months, completion of at least 12, but not more than 15 training sessions and participation in preliminary and final tests. Exclusion criteria were contraindications to the treadmill exercise stress test (TEST) [13].

\section{Study design}

Participants underwent a clinical assessment including the TEST and the 6-MWT at the beginning and after completion of the rehabilitation program. All patients participated in one walking training session a day and 20 minutes of exercises in a sitting position on a chair performed twice a day, 6 times per week.

The exercise stress test was carried out on a Full Vision Inc. treadmill (TMX425, USA), using the Welch Allyn CardioPerfect (USA) workstation and a 3-minute incremental protocol (Modified Bruce 2). The 12-lead ECG and blood pressure (BP) were continuously obtained. The end point was assessed according to criteria of the American Heart Association [13] or reaching 15 points on the 20-grade Borg Scale.

The 6-MWT was conducted in accordance with the American Thoracic Society guidelines [14], on a $25 \mathrm{~m}$ long corridor. HR and BP were measured before and after the test. Predicted walking distance was estimated using an equation $[15,16]$. The 20 -grade Borg Scale for rating perceived exertion was used.

The basis for determining the individual initial training load was the result of the 6-MWT. Predicted peak oxygen uptake $\left(\mathrm{VO}_{2}\right)$ was calculated using the following equation [17]: Peak $\mathrm{VO}_{2}=0.02 \times$ distance $(\mathrm{m})-0.191 \times$ age (years) $-0.07 \times$ weight $(\mathrm{kg})+0.09 \times$ height $(\mathrm{cm})+0.26 \times$ double product $\times 0.001+2.45$.

Distances at $50 \%, 60 \%$ and $70 \%$ of peak $\mathrm{VO}_{2}$ were estimated assuming respectively $50 \%, 60 \%$ and $70 \%$ of baseline peak $\mathrm{VO}_{2}$ and double product values. Age, body weight and height were constant. Values of predicted distances at 50\%, $60 \%$ and $70 \%$ of peak $\mathrm{VO}_{2}$ allowed initial speeds of walking to be determined by dividing distance values by 100 . Depending on general condition, the patient started walking on a flat treadmill (Kettler Track Experience, Germany) with estimated speed of $50 \%, 60 \%$ or $70 \%$ of peak $\mathrm{VO}_{2}$.

The first session lasted 10 minutes, and the next ones were gradually extended to 20 minutes. Walking speed was increased individually depending on the patient's general condition every $2-5$ sessions by $0.2-0.5 \mathrm{~km} / \mathrm{h}$. Maximum speed was limited by the value at which the participant made a switch from walking to running. The ECG, HR and $\mathrm{BP}$ were obtained during all sessions and the 20-grade Borg Scale for rating perceived exertion was used.

Capillary blood from the fingertip was collected before and 3 minutes after the initial and final 6-MWT. Blood lactate concentration (BLC) was determined using the enzymatic spectrophotometric method [18]. Absorbance values were read on the Synergy 2 SIAFRT Multi-Mode Microplate Reader (BioTek Instruments, USA) at a wavelength of $340 \mathrm{~nm}$.

\section{Statistical analysis}

The Shapiro-Wilk test was used to check normality of distribution. Student's $t$-test, the Mann-Whitney test, the Wilcoxon signed rank test, the $\chi^{2}$ test or Fisher's exact test was used to compare variables. Relationships between variables were measured by the Pearson correlation coefficient. Friedman repeated measures analysis of variance by ranks and a post-hoc test were used to analyze repeated measures. Values of $p<0.05$ were considered statistically significant. Statistica version 13.3 software (TIBCO Software Inc., USA) was used for statistical analysis.

\section{Results}

Twenty patients completed the rehabilitation program. Two participants were excluded from the study due to: (1) complaints related to abdominal and iliac aorta aneurysms, (2) bacterial infection of the respiratory tract. Both patients underwent an individual rehabilitation program. The mean age of study participants was $63 \pm 6$ years. Patients began our rehabilitation program a mean of $18 \pm 13$ days following CABG surgery. All participants were diagnosed with chronic ischemic heart disease, 18 (90\%) patients had hypertension and 14 (70\%) had lipid metabolism disorders. All participants received statins, $\beta$-blockers and aspirin. Mean BMI of men was $28.7 \pm 4.3 \mathrm{~kg} / \mathrm{m}^{2}$ and mean left ventricular ejection fraction (LVEF) was $52 \pm 7 \%$. The detailed characteristics of participants were presented in a previous publication [12].

No serious arrhythmias were noted during training sessions and no other adverse events were reported while exercising. Values of the treadmill walking speed during 12 consecutive training sessions are presented in Figure 1. We noted a statistically significant gradual increase in mean treadmill walking speed from session $7(3.1 \pm 0.6 \mathrm{~km} / \mathrm{h}$, $p<0.05)$ (Figure 1). 


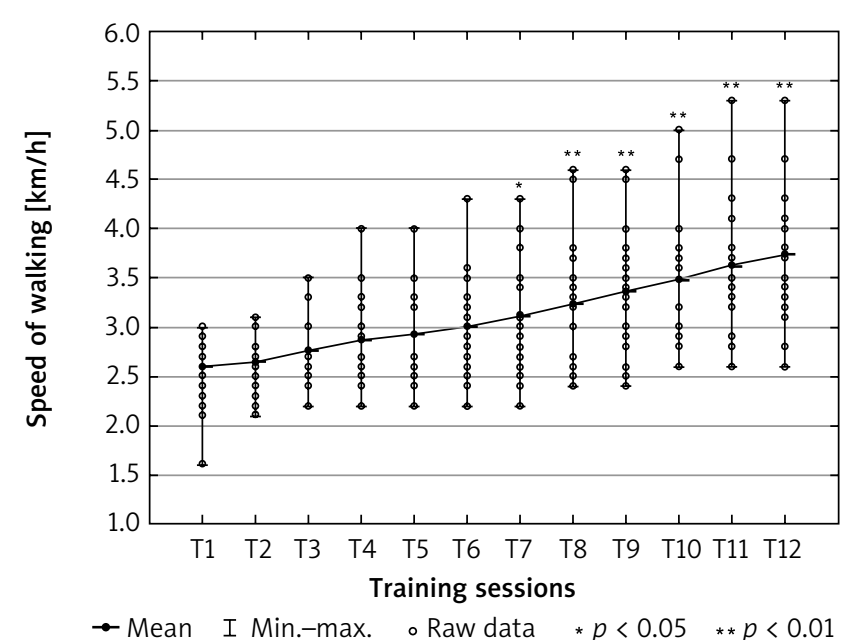

Figure 1. Speed of walking during treadmill walking training sessions

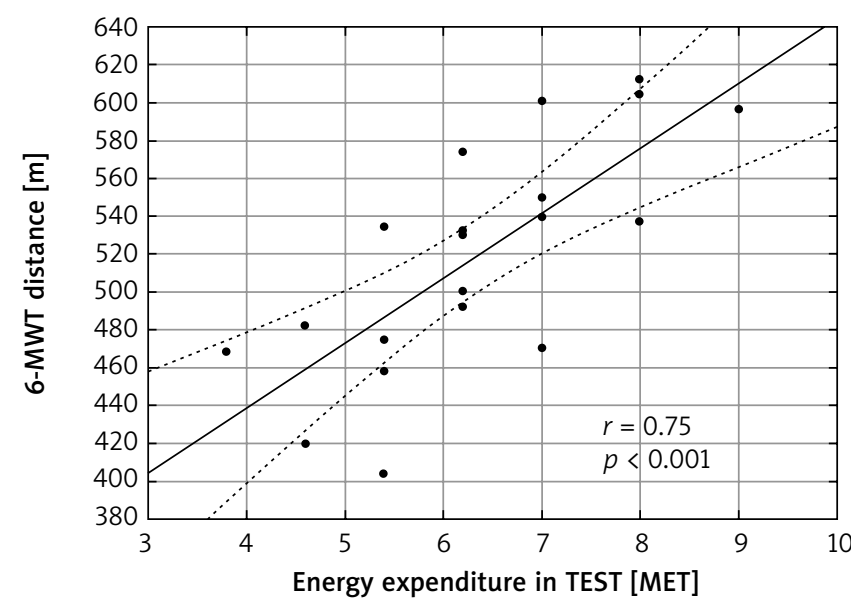

Figure 3. Relationship between 6-minute walk test (6-MWT) distance and energy expenditure in TEST after rehabilitation ( $r$-Pearson correlation coefficient)

After completion of the rehabilitation program, mean 6-MWT distance increased from $420 \pm 80 \mathrm{~m}$ to $519 \pm 61 \mathrm{~m}$ ( $p<0.001$ ), which accounted for $70 \pm 14 \%$ and $86 \pm 11 \%$ of the predicted distance value, respectively. Mean increment of walking distance was $99 \pm 55 \mathrm{~m}(p<0.001)$, which was $27 \pm 6 \%(p<0.001)$ of the baseline distance. The final TEST revealed an increase in mean energy expenditure from 4.4 \pm 1.4 MET to $6.3 \pm 1.3$ MET $(p<0.001)$.

There was a strong positive correlation between 6-MWT distance and energy expenditure in TEST before rehabilitation ( $r=0.60, p=0.005$ ) (Figure 2$)$. After rehabilitation this relationship was very strong $(r=0.75, p<0.001)$ (Figure 3). We also found a strong negative correlation between the baseline 6-MWT distance and distance increment in the final 6-MWT ( $r=-0.66, p=0.002$ ) (Figure 4).

A significant increase in post-6-MWT BLC before and after the rehabilitation was observed (from $1.8 \pm 0.7 \mathrm{mmol} / \mathrm{l}$ to $2.5 \pm 1.6 \mathrm{mmol} / \mathrm{l}, p=0.002$, and from $1.5 \pm 0.3 \mathrm{mmol} / \mathrm{l}$ to $2.6 \pm 1.1, p<0.001$, respectively) (Table I). There were no differences in BLC at rest between the initial and final 6-MWT and after exertion between the initial and final 6-MWT.

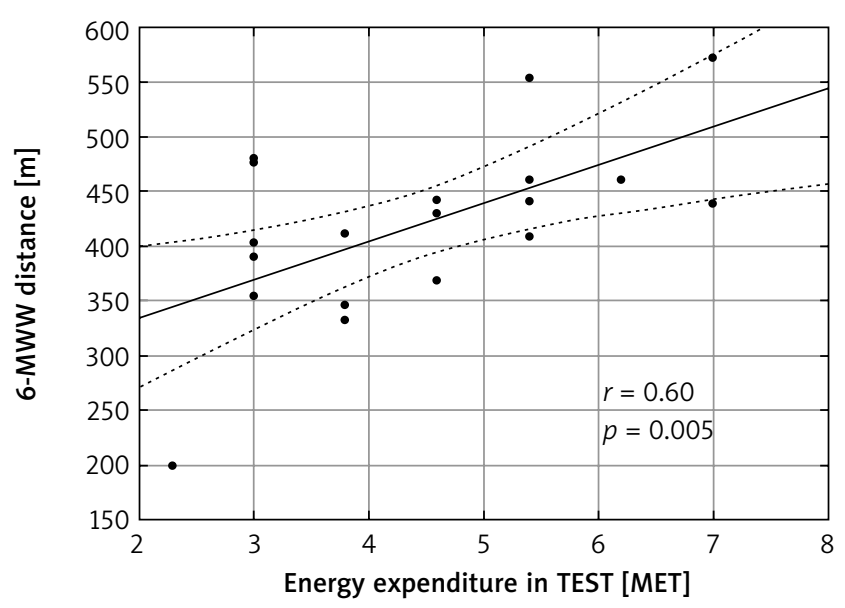

Figure 2. Relationship between 6-minute walk test (6-MWT) distance and energy expenditure in TEST before rehabilitation $(r-$ Pearson correlation coefficient)

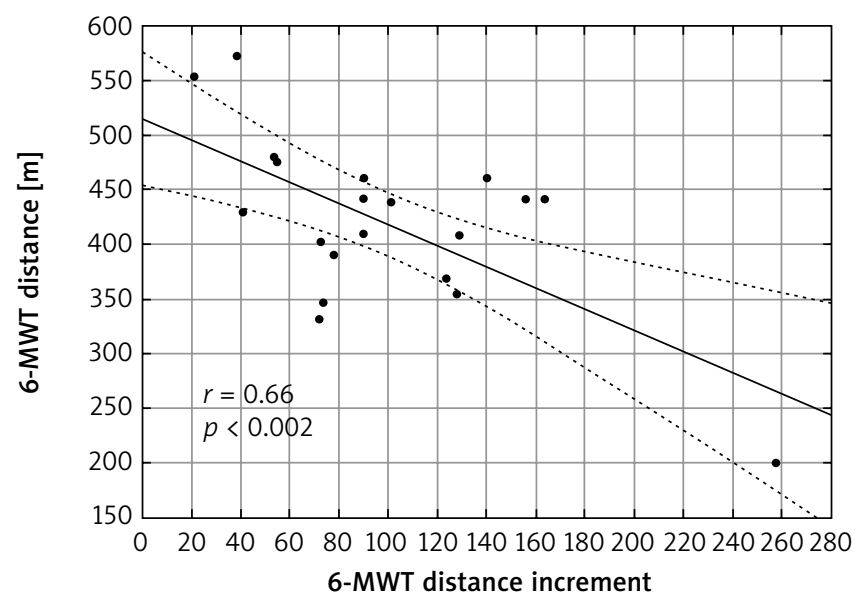

Figure 4. Relationship between 6-minute walk test (6-MWT) distance before rehabilitation and 6-MWT distance increment after rehabilitation ( $r$ - Pearson correlation coefficient)

Table I. Blood lactate concentrations $(\mathrm{mmol} / \mathrm{l})$ in minute walk test (6-MWT)

\begin{tabular}{lccc} 
6-MWT & At rest & After exertion & $P$-value \\
Before rehabilitation & $1.8(0.7)$ & $2.5(1.6)$ & 0.002 \\
\hline After rehabilitation & $1.5(0.3)$ & $2.6(1.1)$ & $<0.001$ \\
\hline
\end{tabular}

Data are presented as mean (SD).

\section{Discussion}

The 6-MWT is a simple tool for measurement of functional status of patients, which does not require specialized equipment or advanced training for medical staff. It enables the assessment of the submaximal level of functional capacity and guiding cardiac rehabilitation, but cannot be performed as a substitute of the cardiopulmonary exercise stress test (CPET) [19]. In this study, we developed a model of continuous training because, in general, patients without initial CPET should begin cardiac rehabilitation with conventional continuous aerobic exercises for several weeks to months [2]. Due to the fact that exercise prescription techniques in cardiac rehabilitation are of criti- 
cal importance since many patients do not undergo baseline CPET to set exercise intensity [2, 3], we used the 6-MWT in our study to determine the initial speed of walking and its increase during walking training sessions on a treadmill in CABG patients.

The most appropriate factors that enable customization of training sessions and individualization of its intensity remain questionable $[3,8]$. Commonly used in clinical practice markers are HR and rate of perceived exertion (RPE) $[2,3]$. Strategies of tailoring the exercise intensity based on determining the target $\mathrm{HR}$ are the most frequent, but are criticized because of not taking into account the chronotropic specificity, which may vary to a great extent in patients with a history of cardiovascular diseases. Chronotropic incompetence may occur as a consequence of drug interactions (e.g. $\beta$-blockers, calcium-channel blockers, ivabradine, amiodarone), dysfunctions of the autonomic nervous system, cardiac alterations and diabetes or other metabolic diseases. In the case of patients with atrial fibrillation, pacemakers and chronotropic incompetence, the target HR is not applicable, and RPE is an alternative way to determine individual training intensity. However, due to the subjectivity of this method, training loads can be easily overestimated or underestimated [3]. Therefore, exercise intensity prescription based on the walking speed appears to be a precise, safe, and efficient approach to individualizing cardiac rehabilitation programs.

Walking speed can be used independently of HR [3], and may be estimated on the basis of walking tests outcomes [2, 3]. Speed values of walking tests are not transferable to a treadmill due to radically different types of effort and energy demands [3]. Our participants began walking on a treadmill with a mean speed of $2.60 \mathrm{~km} / \mathrm{h}$, which was just over $60 \%$ of the average walking speed obtained in the initial 6-MWT. In the $12^{\text {th }}$ training session the mean speed of walking reached $3.74 \mathrm{~km} / \mathrm{h}$, which accounted for nearly $90 \%$ of the average speed achieved during the initial 6-MWT. As shown in Figure 1, the individual initial walking speed ranged from $1.6 \mathrm{~km} / \mathrm{h}$ to $3.0 \mathrm{~km} / \mathrm{h}$, and the final one from $2.8 \mathrm{~km} / \mathrm{h}$ to $4.7 \mathrm{~km} / \mathrm{h}$. We recommended slower walking speeds in a few cases: patient's worse clinical condition, relatively low-grade outcome in the initial 6-MWT and TEST, poor ability of walking on a treadmill or difficulty maintaining balance, short stature of participant and short lower limbs.

In our study, three participants started the first session of walking training at speeds below $2.3 \mathrm{~km} / \mathrm{h}$ (median value of $1.6-3.0 \mathrm{~km} / \mathrm{h}$ ). Their mean value of walking distance in the initial 6-MWT was $293 \pm 81 \mathrm{~m}$, so it seems that patients who walked less than 300 meters should begin training at a lower walking speed. The increment of walking speed in the course of the walking training program was not linear. We tailored the walking speed to the patient's current tolerance of physical effort, being aware that appropriate load progression in a cardiac rehabilitation program is essential to gain maximal health benefits while minimizing the risk of adverse events [7].
The 6-MWT walking distance divided by 100 allows one to estimate the mean walking speed in $\mathrm{km} / \mathrm{h}$. Our participants began to walk on a treadmill at $63 \pm 7 \%$ of the mean speed of walking achieved in the initial 6-MWT. This percentage may be useful in prescribing an initial individual walking speed on the basis of the 6-MWT results in corresponding group of patients. In our study we noted a statistically significant gradual increase in mean treadmill walking speed from session $7(3.1 \pm 0.6 \mathrm{~km} / \mathrm{h}, p<0.05)$, suggesting a mild increase in walking speed during the first half of our rehabilitation program and a moderate increase in the second half. This structure of the training program seems to be both safe and effective in improving exercise tolerance in CABG patients, especially since in our previous study [12] we demonstrated that the walking training we proposed was based on aerobic physical activity and mean BLC during training sessions did not exceed $2.0 \mathrm{mmol} / \mathrm{l}$. According to the literature, $\mathrm{BLC}$ of $0-2 \mathrm{mmol} / /$ is considered normal and a cutoff of $3-5 \mathrm{mmol} / \mathrm{l}$ is used by most authors to define hyperlactatemia [20]. Moreover, the walking training proposed by us proved to improve exercise tolerance of CABG patients as efficiently as the standard interval cycle ergometer training [12].

There are very few studies in which individual training load was determined using 6-MWT speed. This method has been used in pulmonary rehabilitation, mainly in patients with chronic obstructive pulmonary disease (COPD) but not as a standard procedure [20-22]. Authors [21] suggested that high but tolerable walking training intensity, defined as $80 \%$ of mean 6-MWT speed, induced exercise tolerance improvement in COPD patients. Another solution was to prescribe $80 \%, 90 \%$ and $100 \%$ of $6-$ MWT speed during the $1^{\text {st }}, 2^{\text {nd }}$ and $3^{\text {rd }}$ week of rehabilitation, respectively, and then carry out the 6-MWT again to determine $80 \%$, $90 \%$ and $100 \%$ of current $6-$ MWT speed during the next 3 weeks [22].

We found in our study a strong positive correlation between 6-MWT distance and energy expenditure in the TEST before rehabilitation ( $r=0.60, p=0.005$ ) (Figure 2 ). 6-MWT distance directly refers to mean speed of walking during the 6-MWT because the distance value divided by 100 gives the average walking speed. It seems that the relationship of this strength allows one to prescribe safely and effectively an individual intensity of cardiac rehabilitation. Since after rehabilitation this correlation was stronger $(r=0.75, p<0.001$ ) (Figure 3), a follow-up 6-MWT in the course of the rehabilitation program may be considered in order to tailor optimally the training load at a further phase of walking training.

Compared to other studies, the values of correlation coefficients obtained by us were relatively high. Hayta and Korkmaz [23] enrolled patients after CABG surgery to evaluate the reliability of 6-MWT. Before rehabilitation the relationship between 6-MWT distance and energy expenditure in CPET was $r=0.493(p=0.001)$, and after 3 months of rehabilitation it was of similar value $(r=0.456, p=0.001)$, but according to $\mathrm{VO}_{2}$ max in CPET these correlations were 
more diverse and equal to $r=0.297(p=0.05)$ and $r=0.573$ $(p=0.001)$, respectively. Similar to our study, the reliability of 6-MWT increased after cardiac rehabilitation compared to its baseline use. Zanini et al. [24] noted a moderate correlation $(r=0.48, p=0.02)$ between peak $\mathrm{VO}_{2}$ in CPET with 6-MWT distance in patients after 40 days of CABG. Racodon et al. [25] observed a significant correlation between 6MWT distance and the initial and final CPET outcomes $(r=0.5456, p<0.001$ for the initial CPET, $r=0.604, p<0.001$ for the final CPET), confirming the validity of using 6-MWT in cardiac rehabilitation. In turn, Sperandio et al. [26] found a significant relationship between the 6-MWT distance in healthy, middle aged and older adults, and peak $\mathrm{VO}_{2}$ in CPET $\left(R^{2}=0.76, p<0.001\right)$. The authors described the exercise intensity during 6-MWT as moderate to high (80\% of maximum HR obtained in CPET) and concluded that 6-MWT seems to be a valid tool for prescribing walking programs.

A strong negative correlation between the initial 6-MWT distance and the distance increment in the final 6-MWT $(r=-0.66, p=0.002)$ was noted in our study. We speculate that in patients with lower baseline exercise tolerance, who obtained a greater increment of walking distance in the final 6-MWT, the proposed individual training load was sufficient to optimally improve their tolerance of physical activity. Contrarily, in men with higher initial exercise tolerance, who achieved a lower increment in walking distance in the final 6-MWT, the recommended training load could be too low to enable an increment in exercise tolerance to be obtained at a level at least equal to that of participants with lower exercise tolerance. Presumably, a rehabilitation program of higher intensity would be necessary in order to obtain a greater increase in exercise tolerance in these patients. This observation confirms the validity and usefulness of the 6-MWT in the classification of patients to rehabilitation programs with the optimal level of intensity that brings the most health benefits.

Mean resting $B L C$ values before the initial and final 6-MWT were within the normal range, and despite their significant increase after the initial and final 6-MWT, hyperlactatemia was not induced [20]. Very few current studies on 6-MWT lactate concentration exist, and they mainly refer to patients with lung disease. Regarding BLC evaluated 3 minutes after 6-MWT, da L Goulart et al. [27] obtained outcomes comparable to our study. Recovery BLC in studied groups of COPD patients were $2.5 \pm 1.2 \mathrm{mmol} / \mathrm{l}$ and $2.7 \pm 1.1$ $\mathrm{mmol} / \mathrm{l}$. Resting BLC values were slightly higher than in our participants and were $2.9 \pm 1.1 \mathrm{mmol} / \mathrm{l}$ in patients equipped with an expiratory positive airway pressure (EPAP) device and $2.7 \pm 0.9 \mathrm{mmol} / \mathrm{l}$ in non-EPAP patients. During 6-MWT peak BLC values were $2.7 \pm 1.1 \mathrm{mmol} / \mathrm{l}$ in the EPAP group and $3.2 \pm 1.8 \mathrm{mmol} / \mathrm{l}$ in the non-EPAP group. The authors noted that EPAP caused alteration in resting BLC in COPD patients. Chéhère et al. [28] also obtained very similar BLC results in patients with interstitial lung disease. Resting BLC was higher than in our study $(2.31 \pm 0.91 \mathrm{mmol} / \mathrm{l})$, but BLC evaluated immediately after 6-MWT was similar (2.84 $\pm 1.17 \mathrm{mmol} / \mathrm{l})$.
Despite the fact that in our research we have included many practical tips that may turn out to be useful in exercise intensity prescription and cardiac rehabilitation customization, our study has limitations. We enrolled a small group of patients, up to 3 months after CABG surgery, with preserved LVEF, and we did not include women due to the small sample size. In the case of exercise intensity prescription in patients of different characteristics, the results may not be transferred.

\section{Conclusions}

This study showed that the distance covered in 6-MWT is directly associated with energy expenditure in the TEST in men, up to 3 months after CABG surgery. We demonstrated that the 6-MWT can be successfully used in exercise intensity prescription, especially for determining the individual initial training load and load progression, as well as its correction during follow-up tests. Moreover, we proved that the 6-MWT has a high degree of safety and its intensity does not induce hyperlactatemia, even in patients with low exercise tolerance. Additionally, our experience showed that the 6-MWT is easily performed, widely available, well tolerated and thus can be commonly used in everyday clinical practice.

\section{Disclosure}

The authors report no conflict of interest.

\section{References}

1. Taylor A, Yang E. Comparing American and European guidelines for the initial diagnosis of stable ischaemic heart disease. Eur Heart J 2020; 41: 811-815.

2. Mytinger M, Nelson RK, Zuhl M. Exercise prescription guidelines for cardiovascular disease patients in the absence of a baseline stress test. J Cardiovasc Dev Dis 2020; 7: E15.

3. Casillas JM, Gudjoncik A, Gremeaux V, Aulagne J, Besson D, Laroche D. Assessment tools for personalizing training intensity during cardiac rehabilitation: literature review and practical proposals. Ann Phys Rehabil Med 2017; 60: 43-49.

4. Cosentino F, Grant PJ, Aboyans V, Bailey CJ, Ceriello A, Delgado V, Federici M, Filippatos G, Grobbee DE, Hansen TB, Huikuri HV, Johansson I, Jüni P, Lettino M, Marx N, Mellbin LG, Östgren CJ, Rocca B, Roffi M, Sattar N, Seferović PM, Sousa-Uva M, Valensi P, Wheeler DC. 2019 ESC Guidelines on diabetes, pre-diabetes, and cardiovascular diseases developed in collaboration with the EASD. Eur Heart J 2020; 41: 255-323.

5. Knuuti J, Wijns W, Saraste A, Capodanno D, Barbato E, Funck-Brentano C, Prescott E, Storey RF, Deaton C, Cuisset T, Agewall S, Dickstein K, Edvardsen T, Escaned J, Gersh BJ, Svitil P, Gilard M, Hasdai D, Hatala R, Mahfoud F, Masip J, Muneretto C, Valgimigli M, Achenbach S, Bax JJ. 2019 ESC Guidelines for the Diagnosis and Management of Chronic Coronary Syndromes. Eur Heart J 2020; 41: 407-477.

6. Arnett DK, Blumenthal RS, Albert MA, Buroker AB, Goldberger ZD, Hahn EJ, Himmelfarb CD, Khera A, Lloyd-Jones D, McEvoy JW, Michos ED, Miedema MD, Muńoz Daniel, Smith Jr SC, Virani SS, Williams Sr KA, Yeboah J, Ziaeian B. 2019 ACC/AHA Guideline on the Primary Prevention of Cardiovascular Disease: A Report of the American College of Cardiology/American Heart Association Task Force on Clinical Practice Guidelines. Circulation 2019; 140: e596-e646.

7. Squires RW, Kaminsky LA, Porcari JP, Ruff JE, Savage PD, Williams MA. Progression of exercise training in early outpatient cardiac rehabilitation: an official statement from the American Association of Cardiovascular and Pulmonary Rehabilitation. J Cardiopulm Rehabil Prev 2018; 38: 139-146.

8. Pymer S, Nichols S, Prosser J, Birkett S, Carroll S, Ingle L. Does exercise prescription based on estimated heart rate training zones exceed the ventila- 
tory anaerobic threshold in patients with coronary heart disease undergoing usual-care cardiovascular rehabilitation? A United Kingdom perspective. Eur J Prev Cardiol 2020; 27: 579-589.

9. LiWG, Huang Z, Zhang XA. Exercise prescription in cardiac rehabilitation needs to be more accurate. Eur J Prev Cardiol 2020; doi: 10.1177/2047487320936021.

10. Sobczak D, Dylewicz P. The application of walking training in the rehabilitation of patients after coronary artery bypass grafting. Kardiochir Torakochir Pol 2015; 12: 275-287.

11. Main cardiac surgery procedures performed in Poland in 2015 (according to the National Registry of Cardiac Surgery Procedures - KROK, Warsaw, Poland 2016). Kardiochir Torakochir Pol 2016; 13: 185-188.

12. Dolecińska D, Przywarska I, Podgórski T, Dylewicz P. Two early rehabilitation training models in male patients after coronary artery bypass surgery: application of continuous walking training as an alternative to interval cycle ergometer training. Kardiochir Torakochir Pol 2020; 17: 87-93.

13. Fletcher GF, Ades PA, Kligfield P, Arena R, Balady GJ, Bittner VA, Coke LA, Fleg JL, Forman DE, Gerber TC, Gulati M, Madan K, Rhodes J, Thompson PD, Williams MA. Exercise standards for testing and training: a scientific statement from the American Heart Association. Circulation 2013; 128: 873-934.

14. ATS Committee on Proficiency Standards for Clinical Pulmonary Function Laboratories. ATS statement: guidelines for the six-minute walk test. Am J Respir Crit Care Med 2002; 166: 111-117.

15. Duncan MJ, Mota J, Carvalho J, Nevill AM. An evaluation of prediction equations for the 6 minute walk test in healthy European adults aged 50-85 years. PLoS One 2015; 10: e0139629.

16. Duncan MJ, Mota J, Carvalho J, Nevill AM. Correction: an evaluation of prediction equations for the 6 minute walk test in healthy European adults aged 50-85 years. PLoS One 2015; 10: e0142463.

17. Cahalin LP, Mathier MA, Semigran MJ, Dec GW, DiSalvo TG. The six-minute walk test predicts peak oxygen uptake and survival in patients with advanced heart failure. Chest 1996; 110: 325-332.

18. Maughan RJ. A simple, rapid method for the determination of glucose, lactate, pyruvate, alanine, 3-hydroxybutyrate and acetoacetate on a single 20-mul blood sample. Clin Chim Acta 1982; 122: 231-240.
19. Giannitsi S, Bougiakli M, Bechlioulis A, Kotsia A, Michalis LK, Naka KK. 6-minute walking test: a useful tool in the management of heart failure patients. Ther Adv Cardiovasc Dis 2019; 13: 1-10.

20. Minton J, Sidebotham DA. Hyperlactatemia and Cardiac Surgery. J Extra Corpor Technol 2017; 49: 7-15.

21. Zainuldin R, Mackey MG, Alison JA. Prescription of walking exercise intensity from the 6-minute walk test in people with chronic obstructive pulmonary disease. J Cardiopulm Rehabil Prev 2015; 35: 65-9.

22. Chandrasekaran B, Reddy KC. Six-minute walk test as a guide for walking prescription for patients with chronic obstructive pulmonary diseases. Indian J Respir Care 2018; 7: 73-76.

23. Hayta E, Korkmaz Ö. Cardiac rehabilitation increases the reliability of the 6-minute walk test in patients after coronary artery bypass graft surgery. Heart Surg Forum 2017; 20: E247-E251.

24. Zanini M, Santos FS, Martini TF, Naso FCD, Stein R. Association between peak oxygen consumption and six-minute walk test in patients after cardiac surgery. Fisioter Pesqui 2019; 26: 407-412.

25. Racodon M, Porrovecchio A, Pezé T. Utility of the 6-minute walk test in assessing maintenance of physical activity after cardiac rehabilitation. Rech Soins Infirm 2019; 137: 18-25.

26. Sperandio EF, Arantes RL, Matheus AC, Silva RP, Lauria VT, Romiti M, Gagliardi ART, Dourado VZ. Intensity and physiological responses to the 6-minute walk test in middle-aged and older adults: a comparison with cardiopulmonary exercise testing. Braz J Med Biol Res 2015; 48: 349-353.

27. da L Goulart C, San Martin EA, Mansour KMK, Schneiders PB, da Silva ALG. Influence of expiratory positive airway pressure on cardiac autonomic modulation at rest and in submaximal exercise in COPD patients. Braz J Med Biol Res 2018; 51: e7180.

28. Chéhère B, Bougault V, Gicquello A, Wallaert B. Cardiorespiratory response to different exercise tests in interstitial lung disease. Med Sci Sports Exerc 2016; 48: 2345-2352. 